\title{
Exercise effects on adipokines and the IGF axis in men with prostate cancer treated with androgen deprivation: A randomized study
}

\author{
Daniel Santa Mina, PhD; ${ }^{* \neq \neq}$ Michael K. Connor, PhD; ${ }^{\dagger}$ Shabbir M.H. Alibhai, MD; ${ }^{\text {; }}$ Paul Toren, MD, ${ }^{*{ }_{5}}$ \\ Crissa Guglietti, PhD; ${ }^{\dagger}$ Andrew G. Matthew, PhD; ${ }^{*}$ John Trachtenberg, MD; ${ }^{*}$ Paul Ritvo, PhD ${ }^{t f}$
}

*Princess Margaret Cancer Centre, Toronto, ON; †York University, Toronto, ON; *University of Guelph-Humber, Toronto, ON; §University of Toronto, Toronto, ON; ${ }^{ \pm}$Toronto General Hospital, Toronto, ON; ECancer Care Ontario, Toronto, ON

Cite as: Can Urol Assoc J 2013;7(11-12):e692-8. http://dx.doi.org/10.5489/cuaj.235

Published online November 8, 2013.

\section{Abstract}

Background: Androgen deprivation therapy (ADT) has significant deleterious effects on body composition that may be accompanied by unfavourable changes in adipokine levels. While exercise has been shown to improve a number of side effects associated with ADT for prostate cancer, no studies have assessed the effect of exercise on adiponectin and leptin levels, which have been shown to alter the mitogenic environment.

Methods: Twenty-six men with prostate cancer treated with ADT were randomized to home-based aerobic exercise training or resistance exercise training for 24 weeks. Adiponectin, leptin, insulin-like growth factor 1 (IGF-1), insulin-like growth factor binding protein 3 (IGFBP-3) were analyzed by ELISA (enzyme-linked immunosorbent assay), in addition to physical activity volume, peak aerobic capacity, and anthropometric measurements, at baseline, 3 months and 6 months.

Results: Resistance exercise significantly reduced IGF-1 after 3 months ( $p=0.019$ ); however, this change was not maintained at 6 months. At 6 months, IGFBP-3 was significantly increased compared to baseline for the resistance training group ( $p=0.044)$. In an exploratory analysis of all exercisers, favourable changes in body composition and aerobic fitness were correlated with favourable levels of leptin, and favourable leptin:adiponectin and IGF$1:$ IGFBP-3 ratios at 3 and 6 months.

Conclusions: Home-based exercise is correlated with positive changes in adipokine levels and the IGF-axis that may be related to healthy changes in physical fitness and body composition. While the improvements of adipokine markers appear to be more apparent with resistance training compared to aerobic exercise, these findings must be considered cautiously and require replication from larger randomized controlled trials to clarify the role of exercise on adipokines and IGF-axis proteins for men with prostate cancer.

\section{Introduction}

Androgen deprivation therapy (ADT) is indicated for locally advanced and metastatic prostate cancer to slow disease progression; it may be prescribed for several years. ${ }^{1}$ Unfortunately, ADT has significant side effects that compromise physical and psychological well-being, including increased fat mass, and reduced muscle mass and bone density, as well as worsened fatigue and quality of life..$^{1-3}$ In addition to the overt manifestations of androgen suppression, fundamental aspects of endocrine balance are altered through increased fat mass, which contributes to chronic comorbidities and may facilitate tumour progression. Specifically, alternate growth factors, or local adipokines, may support a mitogenic environment and impair disease control with ADT. Lifestyle interventions, such as diet and exercise, have shown to favourably augment human biology and potentially reduce the risk of prostate cancer progression/recurrence, although the mechanisms are not well-understood. ${ }^{4}$

Previous studies assessing the influence of exercise on the mitogenic environment have generally been focused on the effect of exercise on the insulin-like growth factor (IGF) axis. ${ }^{5}$ To date, no study has examined the effect of exercise on adipokines in men with prostate cancer undergoing ADT. A growing body of literature documents the possible influence of leptin and adiponectin on cancer development and progression. ${ }^{6-8}$ Given that adiposity substantively increases after the initiation of ADT and throughout the course of treatment, ${ }^{2,9}$ the resultant deleterious changes to the leptin:adiponectin ratio may support prostate cancer progression. We examine whether 6 months of home-based aerobic and/or resistance exercise training can beneficially increase adiponectin, leptin, and IGF-axis protein levels in patients treated with ADT for hormone-sensitive prostate cancer. 


\section{Methods}

Design

This study was part of a 2-group, prospective randomized trial that examined the effects of home-based aerobic exercise training (AET) or resistance exercise training (RET) for 6 months in men receiving ADT for prostate cancer. ${ }^{10}$ The outcomes of the main trial included physical activity volume, aerobic capacity $\left(\mathrm{VO}_{2}\right.$ peak), musculoskeletal fitness (grip strength), body composition (body fat percentage, waist circumference, body mass index, and chest skinfolds), and self-reported fatigue and quality of life. Given the aforementioned relationship between adipokines and the IGFaxis with physical fitness and cancer cell proliferation, the purpose of this sub-study was to measure these groups of biomarkers in relation to participation in the AET and RET interventions. Due to budgetary restrictions, only a consecutive sub-sample of our original study comprising of the first 26 participants ( 13 from each intervention arm) to complete the 6-month exercise interventions were included.

\section{Subjects}

Participants were recruited from an urban cancer centre between June 2009 and July 2010. Written informed consent was obtained by all participants and procedures were approved by the institutional research ethics board. Patients were included if they (i) were currently receiving ADT for prostate cancer for a planned duration equalling the study duration; (ii) were willing and able to provide informed consent; (iii) had asymptomatic disease, and (iv) had no contraindications to exercise (such as severe coronary artery disease, uncontrolled hypertension [blood pressure $>160 / 95]$, significant congestive heart failure, uncontrolled pain, neurological or musculoskeletal comorbidity inhibiting exercise, or diagnosed psychotic/addictive disorders).

\section{Interventions}

Details of the intervention are presented elsewhere. ${ }^{10}$ Briefly, in the main study patients were randomly allocated to an individualized AET or RET program that began after their baseline evaluation. Participants in each group were encouraged to exercise at home in their assigned modality 5 times per week for 60 minutes per session for 6 months. Participants in the RET group completed 10 exercises targeting the major muscle groups. Using resistance bands, an exercise mat, and a stability ball (provided), participants in the AET program were encouraged to engage in their preferred modality at moderate to vigorous intensity $(60 \%-$ $80 \%$ of measured heart rate maximum). Participants were provided with heart rate monitors (Polar Heart Rate Monitor
FS2, Kempele, Finland) that audibly indicated whether they were outside of their prescribed training zone.

\section{Outcomes}

Participants completed fitness assessments and had serum collection at baseline, 3 and 6 months. Physical fitness measurements and serum collection were conducted by an exercise physiologist with phlebotomy certification. Three measures of body composition were used: body mass index (BMI), waist circumference (WC), and body fat percentage using skinfold calipers (Harpenden Skinfold Calipers, FitSystems Inc, Calgary, AB) at the chest, abdomen, and thigh sites on the right side of the body. ${ }^{11}$ All skinfold measurements were taken by the same outcome assessor with extensive experience in skinfold measurement. Peak volume of oxygen consumed $\left(\mathrm{VO}_{2}\right.$ peak) was indirectly assessed using the modified Bruce treadmill protocol. ${ }^{11,12} \mathrm{VO}_{2}$ peak was calculated using standard American College of Sports Medicine (ACSM) metabolic equations. ${ }^{13}$ The leisure score index (LSI) of the Godin-Shephard Leisure-Time Exercise Questionnaire (GLTEQ) ${ }^{14}$ was used to assess changes in physical activity volume as a proxy of adherence to the exercise program. The LSI is a 3 -item measure that assesses the frequency of mild, moderate and strenuous bouts of exercise performed for 15 minutes or longer during a typical week.

\section{Biomarker analyses}

Twelve millilitres of whole-blood drawn into Vacutainers without additives/preservatives (Becton Dickinson, Franklin Lakes, NJ) was centrifuged at a $3000 \mathrm{rpm}$ for 45 minutes to separate the serum (Laboratory Centrifuge, The Drucker Company, Philipsburg, PA). Serum was stored in aliquots at $-80^{\circ}$ Celsius until assayed. Enzyme-linked immunosorbent assays (ELISAs) were used to quantify plasma levels of insulinlike growth factor-1 (IGF-1), IGF-binding protein subtype 3 (IGFBP-3), leptin and adiponectin. Aliquots of co-culture plasma were incubated in 96-well antibody-coated plates to analyze the proteins with commercially available ELISA kits (IGF-1 and IGFBP-3: DIAsource, Nivelles, Belgium; adiponectin and leptin: Millipore Corp, Billerica, MA). Appropriate standard curves were fitted for each protein measured, and the levels of each protein in patient plasma were calculated based on these standard curves. In each experiment, highand low-level quality controls were included to ensure the validity of the standard curves. Ratios of biomarkers were represented in absolute terms and not molar ratios.

\section{Statistical analysis}

Data were analyzed using SPSS Statistics, version 19.0 (IBM, Armonk, NY). Analysis of covariance (ANCOVA) was used to assess between-group changes from baseline to 3 and 6 
months, controlling for the baseline value of the dependent variable in the model. An exploratory analysis of bivariate correlations was tested using Pearson's correlation coefficient $(r)$ to assess the relationship between the changes in fitness, irrespective of training modality, and biomarkers.

\section{Results}

Of the 66 participants that began the original study (AET=32, RET=34), 44 completed the 6-month intervention period $(\mathrm{AET}=24, \mathrm{RET}=20)$. The 26 participants analyzed in this substudy differed from the other 40 participants of the larger study in terms of weight (mean difference $=-7.5 \mathrm{~kg}, 95 \% \mathrm{Cl}$ : -13.0 to $-2.0, p=0.008$ ) and $\mathrm{BMI}$ (mean difference $=-1.9 \mathrm{~kg} /$ $\mathrm{m}^{2}, 95 \% \mathrm{Cl}:-3.7$ to -0.9$)$. They were similar in terms of all other outcomes at baseline ( $p>0.05$; data not shown). We tallied baseline demographic and disease-specific variables for the 26 participants (Table 1). The mean age of the participants was 72 years and all participants were non-smokers. The AET group had a higher than expected proportion of participants with T3 and T4 disease, as well as higher concentrations of IGFBP-3 than the RET group $(p<0.05)$.

We tallied biomarker and fitness outcome data (Table 2). At 6 months, the AET group demonstrated a significant decrease in IGFBP-3, whereas the RET group showed a significant increase in IGFBP-3. These changes at 6 months corresponded with significant changes in IGF-1:IGFBP-3 ratios, with the AET group increasing the ratio by 0.01 and the RET group decreasing the ratio by 0.01 . Between-group differences in mean change were observed at 6 months for both IGFBP-3 and IGF-1:IGFBP-3 ratios. At 3 months, the RET group demonstrated a significant reduction in IGF-1.

At baseline, there were several significant correlations between fitness outcomes and biological outcomes (data not shown). Body weight, BMI, WC, and body fat percentage were positively correlated to leptin $(r=0.45$ to 0.52 , $p<0.05)$ and leptin:adiponectin $(r=0.53$ to $0.67, p<0.05)$ while being negatively correlated to adiponectin $(r=-0.47$ to $-0.56, p<0.05)$. Changes in physical outcomes and their association with changes in biomarker concentration at 3 months were equated (Table 3). At 3 months, changes in weight, $\mathrm{BMI}$, and $\mathrm{WC}$ were positively correlated with changes in leptin $(r=0.41$ to $0.61, p<0.05)$, while an increase in $\mathrm{VO}_{2}$ peak was correlated with a decrease in leptin concentration levels $(r=0.41, p<0.05)$. Changes in IGF-1:IGFBP-3 ratios were inversely correlated with changes in weight, $\mathrm{BMI}$, and WC $(r=-0.44$ to $-0.46, p<0.05)$, while demonstrating a trend towards a positive relationship with $\mathrm{VO}_{2}$ peak $(r=0.38, p=0.068)$.

Changes in physical outcomes and their association with changes in biomarker concentration at 6 months are presented in Table 4. At 6 months, changes in leptin were positively correlated with changes in weight and BMI $(r=0.52$ to

\begin{tabular}{|c|c|c|c|c|}
\hline Variable & $\begin{array}{c}\text { All } \\
\text { participants } \\
(n=26)\end{array}$ & $\begin{array}{c}\text { AET } \\
(n=13)\end{array}$ & $\begin{array}{c}\text { RET } \\
(n=13)\end{array}$ & $\begin{array}{c}p \\
\text { value }\end{array}$ \\
\hline Age (years) & $72.1(8.4)$ & $\begin{array}{l}70.6 \\
(8.1)\end{array}$ & $\begin{array}{l}73.6 \\
(8.8)\end{array}$ & 0.376 \\
\hline \multicolumn{5}{|l|}{ Categorical variables } \\
\hline Caucasian & $17(65.4)$ & $11(84.6)$ & $8(61.5)$ & 0.242 \\
\hline Married & $19(73.1)$ & $9(69.2)$ & $10(76.9)$ & 0.549 \\
\hline $\begin{array}{l}\text { Post-high school } \\
\text { education }\end{array}$ & $18(69.2)$ & $11(84.6)$ & $7(53.8)$ & 0.328 \\
\hline Retired & $18(69.2)$ & $8(61.5)$ & 10 (76.9) & 0.700 \\
\hline \multicolumn{5}{|l|}{ Gleason score } \\
\hline $6-7$ & $11(42.3)$ & $6(46.2)$ & $5(38.5)$ & \\
\hline 8-10 & $12(46.2)$ & $6(46.2)$ & $6(46.2)$ & 0.288 \\
\hline Not available & $3(11.5)$ & $1(7.7)$ & $2(15.4)$ & \\
\hline \multicolumn{5}{|l|}{ T-Stage } \\
\hline $\mathrm{T} 1 \& \mathrm{~T} 2$ & $16(61.5)$ & $8(61.5)$ & $8(61.5)$ & \\
\hline T3 \& T4 & $8(30.8)$ & $5(38.5)$ & $3(23.1)$ & 0.050 \\
\hline Not available & $2(7.7)$ & $0(0.0)$ & $2(15.4)$ & \\
\hline \multicolumn{5}{|l|}{ Treatment } \\
\hline LHRH-a alone & $12(46.2)$ & $5(38.5)$ & $7(53.8)$ & \\
\hline $\begin{array}{l}\text { LHRH-a + anti- } \\
\text { androgen }\end{array}$ & $12(46.2)$ & $7(53.8)$ & $5(38.5)$ & 0.542 \\
\hline Anti-androgen alone & $2(7.7)$ & $1(7.7)$ & $1(7.7)$ & \\
\hline
\end{tabular}

Data for continuous variables are presented as Mean (SD); $p$-value for between-group differences using independent sample t-test. Data for categorical variables are presented as Frequency ( $\%$ of group); $p$ value for $\chi 2$; LHRH-a: luteinizing hormone-releasing hormone agonist; ADT: androgen deprivation therapy; $A E T$ : aerobic exercise training;

RET: resistance exercise training.

$0.53, p<0.01)$ and negatively correlated with changes in $\mathrm{VO}_{2}$ peak $(r=-0.471, p=0.020)$. Leptin:adiponectin ratio changes were positively correlated with changes in weight and $\mathrm{BMI}(r=0.52$ to $0.53, p<0.01)$ and negatively correlated with body fat percentage $(r=-0.53, p=0.008)$. A positive relationship between WC and IGFI:IGFBP-3 was also observed ( $r=0.432, p=0.035)$, which is discordant with the findings observed at 3 months $(r=-0.456, p=0.025)$.

\section{Discussion}

A large body of literature suggests that IGFs play a role in the incidence of prostate cancer, ${ }^{15-17}$ but only one other study has reported on the effects of exercise on these factors in men already diagnosed. ${ }^{18}$ To our knowledge, no studies have assessed the extent to which leptin and adiponectin can be modified with exercise programs for prostate cancer patients receiving ADT who are vulnerable to deleterious changes to body composition that may negatively influence these biomarkers. There is biological plausibility that altering IGFs and adipokines with healthy lifestyle changes may contribute to improved cancer control and survival rate in prostate cancer. ${ }^{19,20}$ Our findings suggest that a home-based exercise intervention, particularly RET, may have beneficial 
Table 2. Within- and between-group differences in biomarker and fitness outcomes

\begin{tabular}{|c|c|c|c|c|c|c|c|c|}
\hline \multirow[b]{2}{*}{ Variable } & \multicolumn{2}{|c|}{ Baseline } & \multicolumn{2}{|c|}{3 months } & \multicolumn{2}{|c|}{6 months } & \multirow{2}{*}{$\begin{array}{c}\text { Group } \\
\text { difference } \\
\text { in mean } \\
\text { change from } \\
\text { baseline to } 3 \\
\text { months } \\
p \text { value }\end{array}$} & \multirow{2}{*}{$\begin{array}{c}\text { Group } \\
\text { difference } \\
\text { in mean } \\
\text { change from } \\
\text { baseline to } 6 \\
\text { months } \\
p \text { value }\end{array}$} \\
\hline & AET & RET & AET & RET & AET & RET & & \\
\hline Leptin (ng/mL) & $19.9(13.2)$ & $12.8(9.3)$ & $14.9(9.1)$ & $13.6(12.7)$ & $20.6(14.2)$ & $12.1(11.2)$ & 0.475 & 0.496 \\
\hline Adiponectin $(\mu \mathrm{g} / \mathrm{mL})$ & $16.6(6.1)$ & $21.6(10.0)$ & $16.5(7.1)$ & $21.1(11.7)$ & $16.1(18.9)$ & $20.5(9.3)$ & 0.917 & 0.488 \\
\hline Leptin:adiponectin & $\begin{array}{r}1234.23 \\
(865.9)\end{array}$ & $\begin{array}{r}783.6 \\
(807.6)\end{array}$ & $\begin{array}{l}1080.9 \\
(681.9)\end{array}$ & $\begin{array}{r}1038.3 \\
(1508.6)\end{array}$ & $\begin{array}{r}1644.7 \\
(1381.7)\end{array}$ & $\begin{array}{r}882.6 \\
(1263.3)\end{array}$ & 0.278 & 0.548 \\
\hline IGF-1 (ng/mL) & $159.6(55.2)$ & $159.1(51.2)$ & $169.7(67.5)$ & $138.3(42.6)^{\dagger}$ & $161.9(45.9)$ & $146.4(49.5)$ & 0.129 & 0.199 \\
\hline IGFBP-3 (ng/mL) & $\begin{array}{r}5582.7 \\
(1514.3)\end{array}$ & $\begin{array}{r}4360.5 \\
(1370.9)\end{array}$ & $\begin{array}{r}4770.4 \\
(2579.1)\end{array}$ & $\begin{array}{r}4321.3 \\
(1205.5)\end{array}$ & $\begin{array}{r}4259.8 \\
(1349.2)^{\dagger}\end{array}$ & $\begin{array}{r}4887.9 \\
(1639.7)^{\dagger}\end{array}$ & 0.794 & 0.043 \\
\hline IGF-1:IGFBP-3 & $0.03(0.01)$ & $0.04(0.01)$ & $0.13(0.31)$ & $0.03(0.02)$ & $0.04(0.02)^{\dagger}$ & $0.03(0.01)^{\dagger}$ & 0.355 & 0.026 \\
\hline Weight (kg) & $86.2(9.9)$ & $80.3(13.2)$ & $84.4(10.4)^{\dagger}$ & $79.8(13.1)$ & $86.0(10.9)$ & $79.5(13.4)$ & 0.201 & 0.672 \\
\hline WC $(\mathrm{cm})$ & $105.4(9.8)$ & $101.0(11.7)$ & $102.5(8.7)^{\dagger}$ & $100.2(10.4)$ & $103.8(9.9)$ & $98.7(9.6)$ & 0.357 & 0.316 \\
\hline BMI $\left(\mathrm{kg} / \mathrm{m}^{2}\right)$ & $28.5(3.3)$ & $27.4(5.0)$ & $27.9(3.5)^{\dagger}$ & $27.2(5.0)$ & $28.4(3.5)$ & $27.2(5.2)$ & 0.179 & 0.648 \\
\hline Body fat \% & $28.4(6.4)$ & $26.5(9.3)$ & $26.8(5.4)$ & $24.8(8.0)$ & $26.4(5.3)$ & $25.3(8.3)$ & 0.723 & 0.760 \\
\hline $\mathrm{VO} 2-(\mathrm{mL} / \mathrm{kg} / \mathrm{min})$ & $28.8(9.0)$ & $28.7(9.1)$ & $32.0(8.8)$ & $29.1(8.6)$ & $32.8(9.5)^{\dagger}$ & $32.5(10.1)$ & 0.290 & 0.963 \\
\hline PA volume (MET-hrs/wk) & $16.6(10.5)$ & $15.4(18.1)$ & 36.8 (38.7) & $21.3(18.8)$ & $35.5(29.7)$ & $20.3(18.4)$ & 0.221 & 0.759 \\
\hline
\end{tabular}

effects on adipokines and the IGF-axis that could be due to improvements in body composition.

Dysregulation of leptin and/or adiponectin is related to obesity and metabolic syndrome in humans and has been implicated as a risk factor for prostate cancer incidence and progression. ${ }^{6,21-25}$ Adipokines have cell-cycle accelerating and arresting qualities through autocrine and paracrine effects. With respect to prostate cancer, adipokines may exert a paracrine effect on localized disease due to excess adipokine secretion from the retropubic, periprostatic fat pad. ${ }^{23}$ The adipokines, in particular adiponectin and leptin, work in mutually antagonistic ways, with leptin being mitogenic and adiponectin being anti-mitogenic. Therefore, the ideal systemic adaptation for cancer patients would involve relative reductions in leptin and increases in adiponectin, changes that are concomitant with fat loss. In the oncologic literature, there is little research on both the acute and long-term effects of exercise intervention on adiponectin and leptin levels. O'Leary and colleague ${ }^{26}$ demonstrated significant reductions in body weight and fat mass, as well as leptin, but no change in adiponectin in 16 older, obese adults (without cancer) participating in a 12-week AET and stretching program.

Fatouros and colleagues ${ }^{27}$ examined the impact of a 48-week RET program for 50 older men and compared various intensities of training. At post-test, the researchers found that leptin was reduced in each intervention group and adiponectin was increased in the high intensity intervention group only. They additionally reported that changes in leptin were positively correlated with changes in BMI and sum of skinfolds, but negatively correlated with changes in $\mathrm{VO}_{2}$ max. Although our bivariate analyses were exploratory in nature, we observed similar results; reductions in weight, $\mathrm{BMI}$, and WC were associated with reductions in leptin (positive correlation) and increases in $\mathrm{VO}_{2}$ peak were also associated with reductions in leptin (negative association).

IGF increases cellular proliferation by increasing DNA synthesis and by stimulating cyclin D1.28 IGF also has antiapoptotic qualities as it increases the expression of $\mathrm{BCl}$ and suppresses $\mathrm{Bax}^{29}$ to mediate the activity of p53. ${ }^{30}$ IGF has also been shown to stimulate vascular endothelial growth factor (VEGF) in the promotion of angiogenesis. ${ }^{31,32}$ These pro-growth qualities have implicated IGF in prostate cancer. ${ }^{15-17,33}$ The risk of prostate cancer relative to IGF may be more than 4 times greater in those in the highest quartile compared to those in the lowest quartile. ${ }^{33}$ Increased risk is also associated with decreased IGFBP-3 concentrations. ${ }^{34-37}$ Beneficial changes in IGF-axis proteins have been observed in vivo with a low-fat diet; routine exercise in older men at risk for prostate cancer has been shown to reduce cancer cell growth in vitro. ${ }^{30,38,39}$ To assess whether men undergoing ADT for prostate cancer would experience similar changes in the IGF-axis proteins, Bourke and colleagues ${ }^{18}$ randomized 50 patients to 3 months of mixed-modality exercise and dietary advice or usual care. At the end of the intervention, they found no difference between intervention participants and controls in any of the biomarkers. Comparatively, Fairey and colleagues ${ }^{40}$ found beneficial changes in IGF-1, IGFBP- 


\begin{tabular}{|c|c|c|c|c|c|c|}
\hline & $\Delta \mathrm{IGF}-1$ & $\triangle I G F B P-3$ & $\Delta$ Adiponectin & $\Delta$ Leptin & $\Delta$ Leptin:Adiponectin & $\Delta$ IGF-1: IGFBP-3 \\
\hline$\Delta$ Weight $(\mathrm{kg})$ & -0.223 & 0.073 & 0.140 & $0.602^{\ddagger}$ & 0.334 & $-0.452 * *$ \\
\hline$\Delta \mathrm{BMI}\left(\mathrm{kg} / \mathrm{m}^{2}\right)$ & -0.211 & 0.057 & 0.132 & $0.610^{\ddagger}$ & $0.358 *$ & $-0.444^{* *}$ \\
\hline$\Delta \mathrm{WC}(\mathrm{cm})$ & -0.046 & 0.292 & -0.087 & $0.411 * *$ & 0.189 & $-0.456^{* *}$ \\
\hline$\Delta \mathrm{BF} \%$ & -0.311 & -0.313 & 0.139 & -0.109 & -0.060 & -0.067 \\
\hline$\Delta \mathrm{PA}$ Volume (MET-hrs/wk) & 0.119 & -0.017 & 0.139 & -0.026 & -0.040 & 0.117 \\
\hline$\Delta \mathrm{VO}_{2}\left(\mathrm{mlO}_{2} / \mathrm{kg} / \mathrm{min}\right)$ & 0.052 & -0.087 & 0.154 & $-0.406^{* *}$ & -0.159 & $0.379 *$ \\
\hline$\Delta \mathrm{IGF}-1(\mathrm{ng} / \mathrm{mL})$ & 1 & -0.161 & -0.067 & -0.048 & 0.175 & $0.573^{\dagger}$ \\
\hline$\Delta \mathrm{IGFBP}-3(\mathrm{ng} / \mathrm{mL})$ & & 1 & -0.122 & 0.296 & -0.029 & $-0.444^{* *}$ \\
\hline$\Delta$ Adiponectin $(\mu \mathrm{g} / \mathrm{mL})$ & & & 1 & 0.135 & -0.250 & 0.052 \\
\hline$\Delta$ Leptin $(\mu \mathrm{g} / \mathrm{mL})$ & & & & 1 & $0.734^{\ddagger}$ & $-0.565^{\dagger}$ \\
\hline$\Delta$ Leptin:Adiponectin & & & & & 1 & 0.099 \\
\hline
\end{tabular}

Pearson $r$ correlations; BMI: body mass index; PA: physical activity; WC: waist circumference; BF\%: body fat \%; VO$_{2}$ : maximal oxygen consumption peak; IGF-1: insulin-like growth factor 1 ; IGFBP-3: insulin-like growth factor binding protein $3 ;{ }^{*} p \leq 0.1 ;{ }^{* *} p \leq 0.05 ; \dagger p \leq 0.01 ; \neq p \leq 0.001$.

3, and IGF-1:IGFBP-3 in women with breast cancer after 15 weeks of AET compared to usual care. In the present trial, we report a significant increase in IGFBP-3 and decrease in IGF-1:IGFBP-3 with RET, but an increase in these biomarkers with AET after 6 months. These differences were also statistically different between groups. In aggregate, the effects of exercise on the IGF-axis in cancer survivors remain undetermined and require further examination.

There are several limitations that require consideration when interpreting the findings. Foremost is the absence of a control arm to assess changes in biomarkers of participants not participating in an exercise program. This lack of a control group was due to pragmatic considerations; funding availability was linked to the larger study's primary outcomes (quality of life and physical fitness outcomes). The role of the control group within the context of exercise literature during cancer treatment has become a point of contention as most studies indicate benefits for exercise when compared to controls and it may be questioned whether it is ethical to withhold exercise programming for some participants. Second, funding limitations also resulted in a consecutive sub-sample too small to definitively determine the effects of the intervention on the biomarkers assessed. This sub-sample was not randomly selected from the main study's sample and may not be representative of the AET and RET groups as a whole. However, it appears that the groups were matched on many disease/treatment, demographic, and fitness-related variables. Third, we did not have baseline values of our biomarkers in prostate cancer patients that were not on ADT to assess whether ADT caused any changes in the measured cytokines. Fourth, the outcome assessors were not blinded to group allocation, which presents a potential source of bias. Fifth, although several of the findings' $p$ values were below conventional thresholds of $p=0.05$, but not below a Bonferroni-corrected $p=0.0125$, caution is needed in interpreting findings and this work is best viewed as exploratory/hypothesis-generating in need of validation. Finally, the home-based design of the exercise intervention presents challenges regarding compliance and contamination. To address this, future studies should assess the effect of exercise on additional biomarker outcomes in a controlled, supervised setting.

Table 4. Correlation matrix for change in biomarker and physical outcomes from baseline to 6 months

\begin{tabular}{|c|c|c|c|c|c|c|}
\hline & $\Delta \mathrm{IGF}-1$ & $\triangle I G F B P-3$ & $\Delta$ Adiponectin & $\Delta$ Leptin & $\Delta$ Leptin:Adiponectin & $\Delta$ IGF-1: IGFBP-3 \\
\hline$\Delta$ Weight (kg) & 0.098 & -0.179 & -03.146 & $0.529^{\dagger}$ & $0.526^{\dagger}$ & 0.316 \\
\hline$\Delta \mathrm{BMI}\left(\mathrm{kg} / \mathrm{m}^{2}\right)$ & 0.078 & -0.175 & -0.142 & $0.517^{\dagger}$ & $0.524^{\dagger}$ & 0.297 \\
\hline$\Delta \mathrm{WC}(\mathrm{cm})$ & 0.228 & -0.163 & -0.044 & 0.267 & 0.226 & $0.432 * *$ \\
\hline$\Delta \mathrm{BF} \%$ & 0.155 & 0.032 & $0.365^{*}$ & -0.252 & $-0.529^{\dagger}$ & 0.198 \\
\hline$\triangle \mathrm{PA}$ Volume (MET-hrs/wk) & 0.240 & -0.075 & -0.155 & -0.132 & -0.001 & 0.135 \\
\hline$\Delta \mathrm{VO}_{2}\left(\mathrm{mlO}_{2} / \mathrm{kg} / \mathrm{min}\right)$ & 0.142 & 0.045 & 0.087 & $-0.471 * *$ & -0.275 & -0.133 \\
\hline$\Delta \mathrm{IGF}-1(\mathrm{ng} / \mathrm{mL})$ & 1 & 0.170 & 0.340 & 0.173 & 0.150 & 0.246 \\
\hline$\Delta \mathrm{IGFBP}-3(\mathrm{ng} / \mathrm{mL})$ & & 1 & 0.200 & -0.141 & -0.024 & $-0.787^{\ddagger}$ \\
\hline$\Delta$ Adiponectin $(\mu \mathrm{g} / \mathrm{mL})$ & & & 1 & -0.164 & -0.292 & -0.022 \\
\hline$\Delta$ Leptin $(\mu \mathrm{g} / \mathrm{mL})$ & & & & 1 & $0.773^{\ddagger}$ & 0.311 \\
\hline$\Delta$ Leptin:Adiponectin & & & & & 1 & 0.198 \\
\hline
\end{tabular}

Pearson $r$ correlations; BMI: body mass index; PA: physical activity; WC: waist circumference; BF\%: body fat \%; $\mathrm{VO}_{2}$ : maximal oxygen consumption peak; IGF-1: insulin-like growth factor 1 ; IGFBP-3: insulin-like growth factor binding protein $3 ;{ }^{*} p \leq 0.1 ;{ }^{* *} p \leq 0.05 ; \dagger p \leq 0.01 ; \neq p \leq 0.001$. 


\section{Conclusions}

ADT has been consistently shown to induce significant increases in adiposity. We report that 6 months of RET is correlated with significant increases in IGFBP-3 and decreases in IGF-1:IGFBP-3, while AET group demonstrated a decrease in this protein and ratio. We also observed that changes in anthropometric and fitness measures were correlated with changes in leptin levels. Building on previous research that has examined exercise-related changes in IGF-axis proteins, our study is the first to assess the effects of an exercise program on adiponectin and leptin levels in prostate cancer patients receiving ADT. As the research on biomarkers in exercise intervention research for prostate cancer patients remains inconclusive, more research in this field is needed.

Acknowledgement: This research was supported by the Princess Margaret Hospital Foundation.

Competing interests: Dr. Santa Mina, Dr. Connor, Dr. Alibhai, Dr. Toren, Dr. Guglietti, Dr. Matthew, Dr. Trachtenberg, and Dr. Ritvo all declare no competing financial or personal interests.

This paper has been peer-reviewed.

\section{References}

1. Alibhai SM, Gogov S, Allibhai Z. Long-term side effects of androgen deprivation therapy in men with non-metastatic prostate cancer: a systematic literature review. Crit Rev Oncol Hematol 2006;60:201-15. http://dx.doi.org/10.1016/i.critrevonc.2006.06.006

2. Galvao DA, Spry NA, Taaffe DR, et al. Changes in muscle, fat and bone mass after 36 weeks of maximal androgen blockade for prostate cancer. BJU Int 2008;102:44-73. http://dx.doi.org/10.1111/i.1464410X.2008.07539.x

3. Shahinian VB, Yong-Fang K, Freeman JL, et al. Risk of fracture after androgen deprivation for prostate cancer. New Engl J Med 2005;352:154-64. http://dx.doi.org/10.1056/NEJMoa041943

4. Ornish $D$, Weidner $G$, Fair WR, et al. Intensive lifestyle changes may affect the progression of prostate cancer. J Urol 2005;174:1065-70. http://dx.doi.org/10.1097/01.ju.0000169487.49018.73

5. Shaneyfelt $T$, Husein $R$, Bubley $G$, et al. Hormonal predictors of prostate cancer: a meta-analysis. J Clin Oncol 2000; 18:847-53.

6. Kelesidis I, Kelesidis T, Mantzoros CS. Adiponectin and cancer: a systematic review. Br J Cancer 2006;94:1221-5. http://dx.doi.org/10.1038/si.bic.6603051

7. Garofalo C, Surmacz E. Leptin and cancer. J Cell Phys 2006;207:12-22. http://dx.doi.org/10.1002/ icp.20472

8. Dalamaga M, Diakopoulos KN, Mantzoros CS. The Role of Adiponectin in Cancer: A Review of Current Evidence. Endocr Rev 2012;33:547-94. http://dx.doi.org/10.1210/er.2011-1015

9. Smith MR, Finkelstein JS, McGovern FJ, et al. Changes in body composition during androgen deprivation therapy for prostate cancer. J Clin Endocrinol Metab 2002;87:599-603. http://dx.doi.org/10.1210/ ic. 87.2 .599

10. Santa Mina D, Alibhai SMH, Matthew AG, et al. A Randomized Trial of Aerobic versus Resistance Exercise in Prostate Cancer Survivors. J Aging Phys Act 2012; 2013 0ct;21 (4):455-78. Epub 2012 Dec 10.

11. Heyward VH. Advanced fitness assessment and exercise prescription. Windsor, Ontario: Human Kinetics; 2010.

12. Lerman J, Bruce RA, Sivarajan E, et al. Low level dynamic exercises for earlier cardiac rehabilitation: Aerobic and hemodynamic responses. Arch Phys Med Rehabil 1976;57:355-60.

13. American College of Sports Medicine. ACSM's guidelines for exercise testing and prescription. New York: Lippincott Williams and Wikins; 2005.
14. Godin G, Shephard RJ. A simple method to assess exercise behaviour in the community. Can J App Sport Sci 1985;10:141-6.

15. Westerlind KC. Physical activity and cancer prevention: Mechanisms. Med Sci Sports Exerc 2003;35:183440. http://dx.doi.org/10.1249/01.MSS.0000093619.37805.B7

16. Chan JM, Stampfer MJ, Giovannucci E, et al. Plasma insulin-like growth factor-l and prostate cancer risk: a prospective study. Science 1998;279:563-6. http://dx.doi.org/10.1126/science.279.5350.563

17. Wolk A, Mantzoros CS, Andersson SO, et al. Insulin-like growth factor 1 and prostate cancer risk: a population-based, case-control study. J Natl Cancer Inst 1998;90:911-15. http://dx.doi.org/10.1093/ inci/90.12.911

18. Bourke L, Doll H, Crank H, et al. Lifestyle intervention in men with advanced prostate cancer receiving androgen suppression therapy: a feasibility study. Cancer Epidemiol Biomarkers Prev 2011;20:647-57. http://dx.doi.org/10.1158/1055-9965.EPl-10-1143

19. Liu Y, Hu F, Li D, et al. Does physical activity reduce the risk of prostate cancer? A systematic review and meta-analysis. Euro Urol 2011;60:1029-44. http://dx.doi.org/10.1016/i.eururo.2011.07.007

20. Kenfield SA, Stampfer MJ, Giovannucci E, et al. Physical activity and survival after prostate cancer diagnosis in the Health Professionals Follow-Up Study. J Clin Oncol 2011;29:726-32. http://dx.doi. org/10.1200/JC0.2010.31.5226

21. Goktas S, Yilmaz MI, Caglar K, et al. Prostate cancer and adiponectin. Urol 2005;65:1168-72. http:// dx.doi.org/10.1016/i.urology.2004.12.053

22. Michalakis K, Williams CJ, Mitsiades N, et al. Serum adiponectin concentrations and tissue expression of adiponectin receptors are reduced in patients with prostate cancer: a case control study. Cancer Epidemiol Biomarkers Prev 2007;16:308-13. http://dx.doi.org/10.1158/1055-9965.EPI-06-0621

23. Mistry T, Digby JE, Desai KM, et al. Obesity and prostate cancer: a role for adipokines. Eur Urol 2007;52:46-53. http://dx.doi.org/10.1016/i.eururo.2007.03.054

24. Somasundar P, Frankenberry KA, Skinner $\mathrm{H}$, et al. Prostate cancer cell proliferation is influenced by leptin 1 . J Surg Res 2004;1 18:71-82. http://dx.doi.org/10.1016/i.jss.2004.01.017

25. Saglam K, Aydur E, Yilmaz M, et al. Leptin influences cellular differentiation and progression in prostate cancer. J Urol 2003;169:1308-11. http://dx.doi.org/10.1097/01.ju.0000055903.18400.25

26. O'Leary VB, Marchetti CM, Krishnan RK, et al. Exercise-induced reversal of insulin resistance in obese elderly is associated with reduced visceral fat. J Appl Physiol 2006;100:1584-9. http://dx.doi.org/10.1152/ japplphysiol.01336.2005

27. Fatouros IG, Tournis $S$, Leontsini $D$, et al. Leptin and adiponectin responses in overweight inactive elderly following resistance training and detraining are intensity related. J Clin Endocrinol Metabo/ 2005;90:59707. http://dx.doi.org/10.1210/ic.2005-0261

28. Furlanetto RW, Harwell SE, Frick KK. Insulin-like growth factor-l induces cyclin-D1 expression in MG63 human osteosarcoma cells in vitro. Mol Endocrinol 1994;8:510-7. httr://dx.doi.org/10.1210/me.8.4.510

29. Parrizas $M$, LeRoith $D$. Insulin-like growth factor- 7 inhibition of apoptosis is associated with increased expression of the bcl-xL gene product. Endocrinol 1997;138:1355-8. http://dx.doi.org/10.1210/ en.138.3.1355

30. Leung PS, Aronson WJ, Ngo TH, et al. Exercise alters the IGF axis in vivo and increases p53 protein in prostate tumor cells in vitro. J Appl Physiol 2004;96:450-4. http://dx.doi.org/10.1152/japplphysiol.00871.2003

31. Akagi Y, Liu W, Zebrowski B, et al. Regulation of vascular endothelial growth factor expression in human colon cancer by insulin-like growth factor-l. Cancer Res 1998;58:4008-14.

32. Fukuda R, Hirota K, Fan F, et al. Insulin-like growth factor 1 induces hypoxia-inducible factor 1-mediated vascular endothelial growth factor expression, which is dependent on MAP kinase and phosphatidylinositol 3-kinase signaling in colon cancer cells. J Biol Chem 2002;277:38205-11. http://dx.doi.org/10.1074/ ibc.M203781200

33. Stattin $P$, Rinaldi $S$, Biessy $C$, et al. High levels of circulating insulin-like growth factor-l increase prostate cancer risk: a prospective study in a population-based nonscreened cohort. J Clin Oncol 2004;22:3104-12. http://dx.doi.org/10.1200/JC0.2004.10.105

34. Lopez JB, Sahabudin RM, Chin LP. Are plasma insulin-like growth factor I (IGF-I) and IGF-binding protein 3 (IGFBP-3) useful markers of prostate cancer? Int I Biol Markers 2004;19:164-7.

35. Miyata Y, Sakai H, Kanda S, et al. Expression of insulin-like growth factor binding protein-3 before and after neoadiuvant hormonal therapy in human prostate cancer tissues: correlation with histopathologic effects and biochemical recurrence. Urol 2004;63:1 184-90. http://dx.doi.org/10.1016/i.urology.2004.02.015

36. Djavan $B$, Waldert $M$, Seitz $C$, et al. Insulin-like growth factors and prostate cancer. World I Urol 2001;19:225-33.

37. Russell PJ, Bennett S, Stricker P. Growth factor involvement in progression of prostate cancer. Clin Chem 1998;44:705-23.

38. Ngo TH, Barnard RJ, Tymchuk CN, et al. Effect of diet and exercise on serum insulin, IFG-I, and IFGBP-1 levels and growth of LNCaP cells in vitro. Cancer Causes Control 2002;13:929-35. http://dx.doi. org/10.1023/A:1021911517010 
Santa Mina et al.

39. Barnard RJ, Ngo TH, Leung PS, et al. A low-fat diet and/or strenuous exercise alters the IGF axis in vivo and reduces prostate tumor cell growth in vitro. Prostate 2003;56:201-6. http://dx.doi.org/10.1002/ pros. 10251

40. Fairey AS, Courneya KS, Field CJ, et al. Effects of exercise training on fasting insulin, insulin resistance, insulin-like growth factors, and insulin-like growth factor binding proteins in postmenopausal breast cancer survivors: a randomized controlled trial. Cancer Epidemiol Biomarkers Prev 2003;12:721-7.
Correspondence: Dr. Daniel Santa Mina, 207 Humber College Boulevard, Rm GH - 308 - G, Toronto, ON M9W 5L7; fax: 416-798-3293; daniel.santamina@guelphhumber.ca 